\title{
Magnet-assisted endoscopic choledochoduodenostomy in anomalous opening of the common bile duct into the duodenal bulb
}

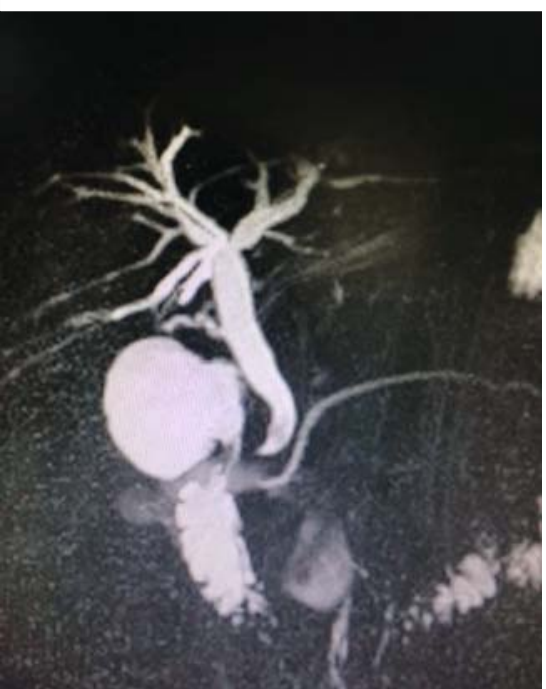

- Fig. 1 Magnetic resonance cholangiopancreatography (MRCP) image showing the dilated common bile duct with a distal hook-shaped narrowing, together with the enlarged duodenal bulb due to the narrowed apex.

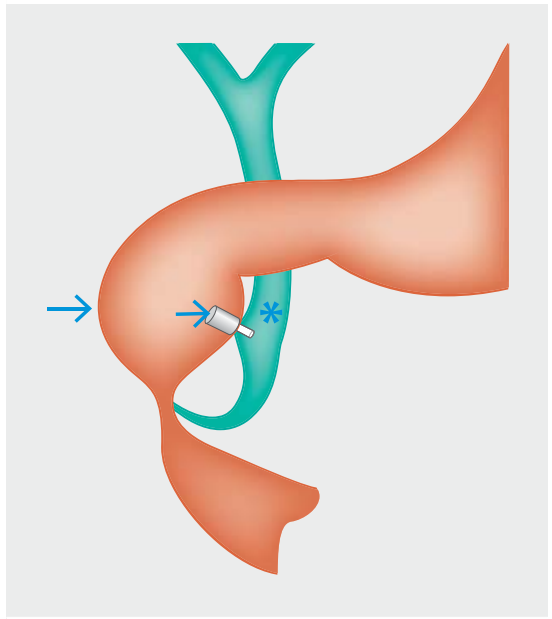

- Fig. 2 An illustration of magnet-assisted endoscopic choledochoduodenostomy applied to a distally hook-shaped narrowed common bile duct (asterisk) opening into an enlarged duodenal bulb due to apical narrowing (arrow). The arrowhead represents the alignment of the magnets.

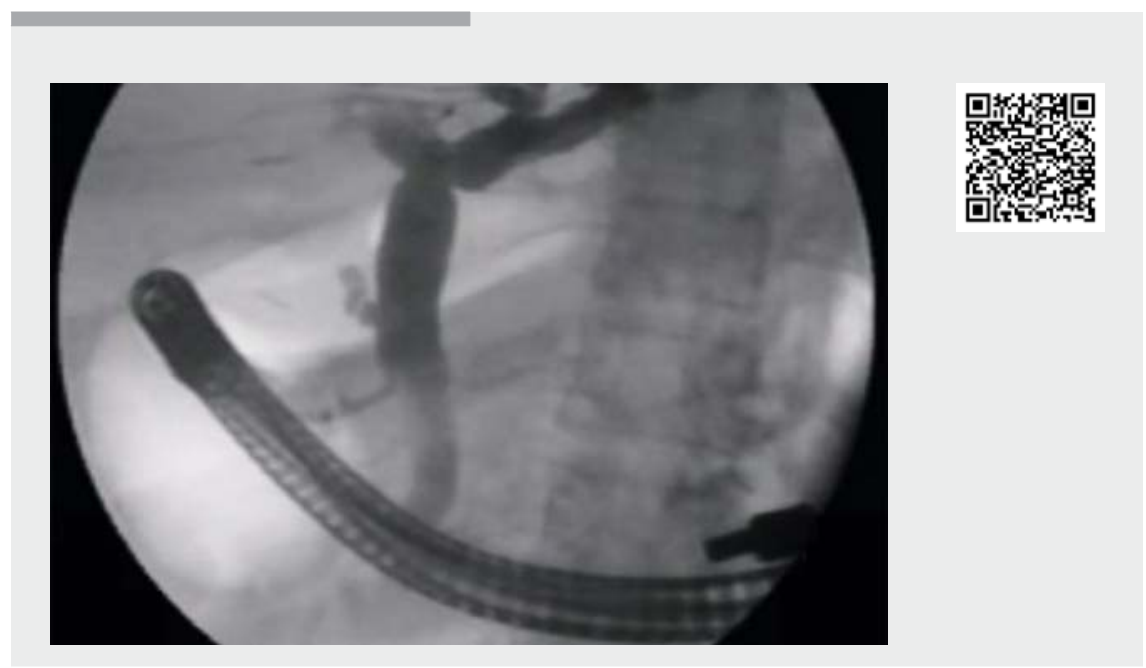

Video 1 Anomalous opening of the common bile duct into the duodenal bulb that has caused recurrent choledocholithiasis treated with a new method, magnet-assisted choledochoduodenostomy.

Variations of the biliary opening into the enteral lumen may cause conditions such as biliary colic, recurrent cholangitis, and pneumobilia, among others [1,2]. Surgery is the main treatment, but it has high morbidity and mortality rates. Magnetic compression anastomosis (MCA) is a novel technique that has been widely applied in the gastrointestinal system [3]. Herein, we present a patient with an anomalous biliary opening that was treated with magnet-assisted endoscopic choledochoduodenostomy (MECD), which was based on the MCA technique.

A 36-year-old man with a history of biliary sepsis was referred to our clinic with the need for recurrent endoscopic retrograde cholangiopancreatography (ERCP) procedures. Previous ERCP examinations had demonstrated an anomalous opening of the common bile duct (CBD) into the duodenal bulb, which led to a hookshaped narrowing of the distal CBD ( Fig. 1). Previous interventions using ERCP had been difficult to perform owing to apical bulb narrowing and had remained inconclusive.
It was decided to perform MECD ( $>$ Fig. 2; - Video 1) to avoid the possible complications of bilioenteric diversion surgery. A $3.5 \times 10-\mathrm{mm}$ N35 Neodymium magnet was inserted into the distally narrowed CBD using the through-the-scope technique. Subsequently, a $10 \times 10-\mathrm{mm}$ N35 Neodymium magnet was inserted into the duodenal bulb endoscopically with the help of a snare. Fluoroscopy confirmed the alignment of the magnets ( Fig.3a). After 20 days, the magnets were seen to be coupled on fluoroscopy ( $\vee$ Fig. $\mathbf{3 b}$ b) and they were removed endoscopically ( Fig.4). Cannulation and radiocontrast examination of this newly formed choledochoduodenal fistula demonstrated a well-formed tract from the biliary system through to the duodenum. A coated metal stent was inserted to preserve and enlarge the new opening. In conclusion, avoidance of the hookshaped distal narrowing and maintenance of a free passage for bile with the MECD technique protected the patient from future attacks stemming from biliary stasis, as well as from the complica- 

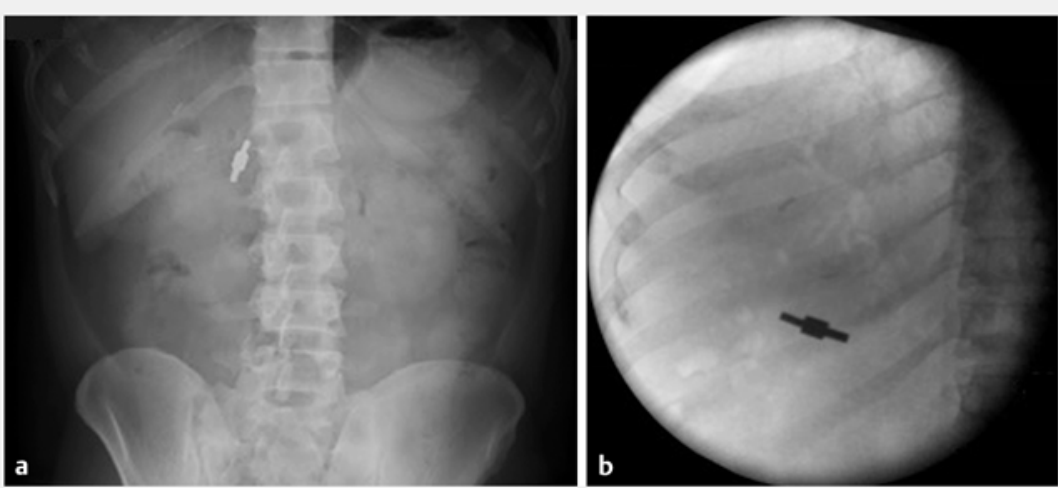

- Fig. 3 Fluoroscopic images showing: a the aligned magnets on day 6 of the procedure; b the coupled magnets on day 20 of the procedure (seen horizontally when compared to the position on day 6).

tions of bilioenteric diversion surgery. To the best of our knowledge, the MECD technique was used for the first time in the presented case.

\section{Endoscopy_UCTN_Code_TTT_1AR_2AG}

\section{Competing interests}

The authors declare that they have no conflict of interest.

The authors

\section{Bülent Ödemiș ${ }^{1}$, Batuhan Bașpınar ${ }^{1}$, Serkan} Torun ${ }^{2}$, Orhan Coşkun ${ }^{3}$

1 Department of Gastroenterology and Hepatology, Ankara City Hospital, Ankara, Turkey

2 Faculty of Medicine, Department of Gastroenterology, Düzce University, Düzce, Turkey

3 Department of Gastroenterology, Sabuncuoğlu Şerefeddin Teaching Hospital, Amasya University, Amasya, Turkey

\section{Corresponding author}

\section{Batuhan Başpınar, MD}

Department of Gastroenterology and Hepatology, Ankara City Hospital, Bilkent Avenue, 06800, Çankaya, Ankara, Turkey batuhanbaspinar@gmail.com

\section{References}

[1] Kubota T, Fujioka T, Honda S et al. The papilla of Vater emptying into the duodenal bulb. Report of two cases. Jpn J Med 1988; 27: 79-82

[2] Disibeyaz S, Parlak E, Cicek B et al. Anomalous opening of the common bile duct into the duodenal bulb: endoscopic treatment. BMC Gastroenterol 2007; 7: 26

[3] Graves CE, Co C, Hsi RS et al. Magnetic compression anastomosis (Magnamosis): Firstin-human trial. J Am Coll Surg 2017; 225: 676-681

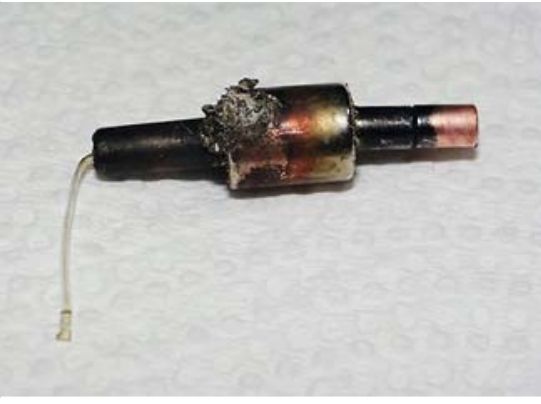

- Fig. 4 Photograph of the coupled magnets after their removal.
Bibliography

DOI https://doi.org/10.1055/a-1144-2378

Published online: 17.4.2020

Endoscopy 2020; 52: E386-E387

(c) Georg Thieme Verlag KG

Stuttgart · New York

ISSN 0013-726X

\section{ENDOSCOPY E-VIDEOS}

https://eref.thieme.de/e-videos

口回 Endoscopy E-Videos is a free access online section, reporting 回: on interesting cases and new techniques in gastroenterological endoscopy. All papers include a high quality video and all contributions are freely accessible online.

This section has its own submission website at https://mc.manuscriptcentral.com/e-videos 